\title{
Effect of different scenarios for selective dry-cow therapy on udder health, antimicrobial usage, and economics
}

\author{
C. G. M. Scherpenzeel, ${ }^{\star 1}$ I. E. M. den Uijl, ${ }^{*}$ G. van Schaik, ${ }^{\dagger} \dagger$ R. G. M. Olde Riekerink, ${ }^{*}$ H. Hogeveen, $† \ddagger$ \\ and T. J. G. M. Lam*† \\ ${ }^{*}$ GD Animal Health, PO Box 9, 7400 AA Deventer, the Netherlands \\ †Department of Farm Animal Health, Utrecht University, PO Box 80151, 3508 TD Utrecht, the Netherlands \\ $\ddagger$ Chair Group Business Economics, Wageningen University, PO Box 8130, 6700 EW Wageningen, the Netherlands
}

\section{ABSTRACT}

The goal of dry-cow therapy (DCT) is to reduce the prevalence of intramammary infections (IMI) by eliminating existing IMI at drying off and preventing new IMI from occurring during the dry period. Due to public health concerns, however, preventive use of antimicrobials has become questionable. In this study, we evaluated the effects of 8 scenarios for selecting animals for DCT, taking into account variation in parity and cow-level somatic cell count (SCC) at drying off. The aim of this study was to evaluate udder health, antimicrobial usage, and economics at the herd level when using different scenarios for selecting cows for DCT. To enable calculation and comparison of the effects of different scenarios to select cows for DCT in an "average" herd, we created an example herd, with a virtual herd size of 100 dairy cows to be calving during a year. Udder health, antimicrobial usage, and economics were evaluated during the dry period and the first $100 \mathrm{~d}$ in lactation, the period during which the greatest effect of DCT is expected. This leads to an estimated 13,551 cow-days at risk during a year in a 100-cow dairy herd. In addition to a blanket DCT (BDCT) scenario, we developed 7 scenarios to select cows for DCT based on SCC. The scenarios covered a range of possible approaches to select low-SCC cows for DCT, all based on cow-level SCC thresholds on the last milk recording before drying off. The incidence rate of clinical mastitis in the example herd varied from 11.6 to 14.5 cases of clinical mastitis per 10,000 cow-days at risk in the different scenarios, and the prevalence of subclinical mastitis varied from $38.8 \%$ in scenario 1 (BDCT) to $48.3 \%$ in scenario 8. Total antimicrobial usage for DCT and clinical mastitis treatment varied over the scenarios from 1.27 (scenario 8) to 3.15 animal daily dosages

Received June 15, 2015.

Accepted December 9, 2015.

${ }^{1}$ Corresponding author: c.scherpenzeel@gdanimalhealth.com
(BDCT), leading to a maximum reduction in antimicrobial usage of $60 \%$ for scenario 8 compared with BDCT. The total costs for each of the scenarios showed little variation, varying from $€ 4,893$ for scenario 5 to $€ 5,383$ for scenario 8 . The effect of selective DCT compared with BDCT on udder health, antimicrobial usage, and economics is influenced by the SCC criteria used to select cows for DCT. Scenario 2 resulted in the lowest increases in clinical and subclinical mastitis compared with BDCT. The greatest reduction in antimicrobial usage was achieved under scenario 8 . From an economic perspective, lowest costs were achieved with scenario 5 . Drying off dairy cows with antimicrobials has an effect on udder health, antimicrobial usage, and economics.

Key words: mastitis, antimicrobial reduction, dry-cow therapy, economics

\section{INTRODUCTION}

Since the 1970s, the 5 Points Mastitis Control Plan has been used successfully to manage and control contagious mastitis (Dodd et al., 1969). One of the points recommended is the use of dry-cow therapy (DCT) to reduce the level of IMI by eliminating IMI present at drying off and preventing new IMI from developing during the dry period (Neave et al., 1969). A study in the 1990s showed that the use of dry-cow antimicrobials reduced clinical mastitis (CM) compared with untreated controls (Schukken et al., 1993). In that study, however, a within-cow comparison on the effect of DCT was performed without separating uninfected and infected cows (Schukken et al., 1993). Bradley and Green (2000) showed that approximately $50 \%$ of quarters with CM due to environmental pathogens in the first 100 DIM were infected with the causative pathogen during the dry period, even though they were treated with drycow antimicrobials. Thus, DCT has consequences for udder health during both the dry period and lactation. In the United States and Canada, uptake of blanket dry cow therapy (BDCT) by dairy herds is estimated 
at 72 and $88 \%$ respectively (USDA, 2008; Dufour et al., 2012). In the Netherlands, approximately $90 \%$ of all dairy cows were treated with dry-cow antimicrobials in the period from 2005 to 2010 (Lam et al., 2013). In the United Kingdom, DCT use is estimated to be even higher, with $99 \%$ of dairy cows treated at drying off (Berry and Hillerton, 2002). In 2013, antimicrobial use for DCT counted for $49 \%$ of the total antimicrobial use in the Dutch dairy industry (SDa, 2014).

Although the relationship between antimicrobial use and the development of antimicrobial resistance in bacteria is complex and unclear (Oliver et al., 2011), correlation between veterinary antimicrobial use and antimicrobial resistance in animal pathogens is likely (Chantziaras et al., 2014). Global concern about antimicrobial resistance propagates prudent and restricted use of antimicrobials, including DCT, in the dairy industry (Oliver et al., 2011). Therefore, in the Netherlands, preventive use of antimicrobials in DCT is no longer allowed and selective dry-cow therapy (SDCT) was introduced in 2013 as an alternative for BDCT. To correctly select cows for curative use of antimicrobials in DCT, IMI at drying off need to be identified. This identification can be based on different criteria, such as SCC, bacteriological culture, and CM history (Torres et al., 2008; Rajala-Schultz et al., 2011). Herdlevel parameters, such as bulk milk SCC can also be taken into account. Application of a SDCT regimen, based on withholding DCT from multiparous cows with SCC $<250,000$ cells $/ \mathrm{mL}$ and primiparous cows with SCC $<150,000$ cells $/ \mathrm{mL}$ at the last milk recording before drying off, has been evaluated (Scherpenzeel et al., 2014). This approach significantly increased the incidence rate of CM (IRCM) and subclinical mastitis (SCM) and had potential consequences for animal welfare and economics but resulted in a substantial decrease in antimicrobial usage.

Farmers' decision-making on DCT is based not only on the description of the udder health situation in terms of disease (e.g., incidence of CM or SCM) but also in monetary terms (e.g., economic losses; Hogeveen et al., 2011). Earlier work showed that SDCT is attractive from an economic point of view (Huijps and Hogeveen, 2007). In that study, however, the probability of treatment for SDCT depended on the sensitivity and specificity of the selection procedure: with a high sensitivity of selection, infected cows are more likely to be treated; with a high specificity, uninfected cows are less likely to be treated. It was assumed that the right animals, those who have not developed IMI, were selected and not treated with antimicrobials at drying off but the authors did not describe how to select those animals. Given the variety in possible approaches for selecting cows for DCT when implementing SDCT in practice, and the consequences of that for udder health and economics, selection criteria need further attention. Therefore, in this study, we evaluated the effects of 8 scenarios for selecting animals for DCT, taking into account variation in parity and cow-level SCC at drying off. The aim of this study was to evaluate udder health, antimicrobial usage, and economics at the herd level when using different scenarios for selecting cows for DCT.

\section{MATERIALS AND METHODS}

\section{Field Data}

A field trial was carried out between June 2011 and March 2012 in the Netherlands. In total, 1,657 lactating cows $[657$ primiparous cows (40\%) and 1,000 multiparous cows (60\%)] from 97 herds were dried off in the study and were followed from drying off until 100 DIM. Bulk milk SCC of the participating herds varied from 41,000 to 387,000 cells $/ \mathrm{mL}$, with an average of 184,000 cells $/ \mathrm{mL}$. The effect of SDCT was evaluated using a split-udder design in which 2 lateral quarters of each cow were treated with antimicrobials and the 2 contralateral quarters remained as untreated controls. All cows enrolled had a low SCC at the last milk recording before drying off. Low SCC was defined as $<150,000$ cells $/ \mathrm{mL}$ for cows at the end of their first lactation and $<250,000$ cells/mL for older cows, thresholds used in the Dutch national milk recording for indicating an elevated SCC (de Haas et al., 2008). A more detailed description of this field trial can be found in Scherpenzeel et al. (2014).

\section{Age Groups}

Because different age groups have different characteristics with regard to the dry period and udder health, cows in first and later lactations were judged separately. The youngest group is the group of animals after their first calving. In this study, this group was referred to as heifers (group $\mathbf{H}$ ). At the end of the first lactation, these animals are dried off. Mastitis in the first dry period, and 100 DIM after (the second) calving is related to the dry-cow treatment at the end of the first lactation. This group of animals, until they were 100 DIM, was referred to as first dry period (FDP) animals. Multiparous cows are animals that have calved at least twice. Cows that were dried off for the second or later time were referred to as multi dry period (MDP) animals during their dry period and the first 100 DIM of the subsequent lactation. As such, terminology related to parity was considered as parity at drying off. 


\section{Example Herd}

To enable calculation and comparison of the effect of the different scenarios to select cows for DCT in an "average" herd, we created an example herd. This herd had a virtual herd size of 100 dairy cows calving during a year, with an average age distribution of Dutch dairy herds following the Royal Dutch Cattle Syndicate, in which $33 \%$ of animals had calved once (heifers), $26 \%$ had calved twice (FDP animals), and $41 \%$ had calved more frequently (MDP animals; CRV, 2014). The number of cows calving in an age group was used as the number of cows for dry-cow treatment decisions. Therefore, of the 100 cows, 33 had no dry period, 26 were FDP animals, and 41 were MDP animals. The distribution of high-SCC and low-SCC animals was based on cow-level SCC data from the last milk recording before drying off of all animals of the 97 herds included in the field trial (Table 1). The proportion of FDP animals below the trial threshold of 150,000 cells $/ \mathrm{mL}$ was $80.5 \%$. The proportion of MDP animals below the trial threshold of 250,000 cells $/ \mathrm{mL}$ was $71.6 \%$. Thus, the example herd had $19.5 \%$ of FDP $(\mathrm{n}=5)$ and $28.4 \%$ of MDP $(\mathrm{n}=12)$ animals being above the trial SCC threshold. The cows below the trial threshold were subdivided into cows above and below the scenario threshold as described below, which was based on the distributions found in the study of Scherpenzeel et al. (2014).

\section{Scenarios}

Besides a BDCT scenario, 7 scenarios to select cows for DCT based on SCC were developed (Table 2). In all SDCT scenarios, cows exceeding the trial threshold at the last milk recording before drying off (FDP $\geq 150,000$ cells $/ \mathrm{mL}$ and MDP $\geq 250,000$ cells $/ \mathrm{mL}$ ) were dried off with antimicrobials. The scenarios cover a range of possible approaches to select low-SCC cows for DCT, all based on cow-level SCC scenario thresholds on the last milk recording before drying off. Three scenarios used the same scenario threshold for all cows, not differentiating between FDP and MDP animals, being 50,000 (scenario 2), 100,000 (scenario 3), and 150,000 cells/mL (scenario 4). Four scenarios differentiated scenario thresholds for FDP and MDP animals (FDP/MDP) and were 150,000/50,000 (scenario 5), $150,000 / 100,000$ (scenario 6), 150,000/200,000 (scenario 7 ), and 150,000/250,000 cells/mL (scenario 8).

Per scenario, the 100 cows in the example herd were divided into 7 groups according to parity and cow SCC at drying off as presented in Table 3. Distribution of cows over the different SCC groups was in accordance with the average SCC distribution in the 97 herds in the field trial. Based on these groups, cows were select-
Table 1. Cow-level SCC distribution at the end of first and later lactations of all cows of the 97 herds in the field trial

\begin{tabular}{lcc}
\hline $\begin{array}{l}\text { SCC category } \\
\left(\times 10^{3} \text { cells } / \mathrm{mL}\right)\end{array}$ & $\begin{array}{c}\text { First } \\
\text { lactation }(\%)\end{array}$ & $\begin{array}{c}\text { Later } \\
\text { lactation }(\%)\end{array}$ \\
\hline $0-49$ & 40.7 & 14.0 \\
$50-99$ & 27.5 & 19.9 \\
$100-149$ & 12.3 & 17.5 \\
$150-199$ & 5.9 & 11.9 \\
$200-249$ & 3.9 & 8.3 \\
$\geq 250$ & 9.7 & 28.4 \\
\hline
\end{tabular}

ed to be eligible for DCT when meeting the threshold values in the different scenarios, except the group of heifers (group $\mathrm{H}, \mathrm{n}=33$ ) that, obviously, had not been dried off. Subsequently, data from the selected cows in each scenario were used based on the data as available from the 97 herds and were analyzed with respect to CM, number of quarters with SCC $>200,000$ cells $/ \mathrm{mL}$ (QSCC > 200) at 14 DIM, antimicrobial usage, and economics. Data of these 4 parameters were used for the related groups of animals in each of the scenarios. The FDP animals with SCC less than the scenario threshold at drying off were dried off without antimicrobials (group FDPLNA), and the FDP animals with SCC greater than the scenario threshold but less than 150,000 were dried off with antimicrobials (group FDPLWA). The MDP animals with SCC less than the scenario threshold were dried off without antimicrobials (MDPLNA), and the MDP animals with SCC greater than the scenario threshold but less than 250,000 were dried off with antimicrobials (MDPLWA). In all scenarios in the example herd, FDP animals with SCC $\geq 150,000$ at drying off (group FDPHWA, $\mathrm{n}=5$ ) and MDP animals with SCC $\geq 250,000$ at drying off (group MDPHWA, $\mathrm{n}=12$ ) were dried off with antimicrobials. For groups H, FDPHWA, and MDPHWA, no data were collected in the above-described field trial and, therefore, values were based on literature. Before analy-

Table 2. Eight scenarios with SCC thresholds to select cows for treatment with antimicrobials at drying off, based on cow-level SCC at the last milk recording before drying off, for first and later dry periods

\begin{tabular}{lcc}
\hline \multicolumn{2}{c}{$\operatorname{SCC}\left(\times 10^{3}\right.$ cells $\left./ \mathrm{mL}\right)$} \\
\cline { 2 - 3 } Scenario & $\begin{array}{c}\text { At end of first } \\
\text { lactation }\end{array}$ & $\begin{array}{c}\text { At end of later } \\
\text { lactations }\end{array}$ \\
\hline 1 & $>0$ & $>0$ \\
2 & $>50$ & $>50$ \\
3 & $>100$ & $>100$ \\
4 & $>150$ & $>150$ \\
5 & $>150$ & $>100$ \\
6 & $>150$ & $>200$ \\
7 & $>150$ & $>250$ \\
\hline
\end{tabular}


Table 3. Distribution of cows in an example dairy herd of 100 calving cows for the 7 groups $^{1}$ in 8 different scenarios (1-8) with their cow-level SCC thresholds $\left(\times 10^{3}\right.$ cells $\left./ \mathrm{mL}\right)$, for heifers and first dry period and multi dry period animals

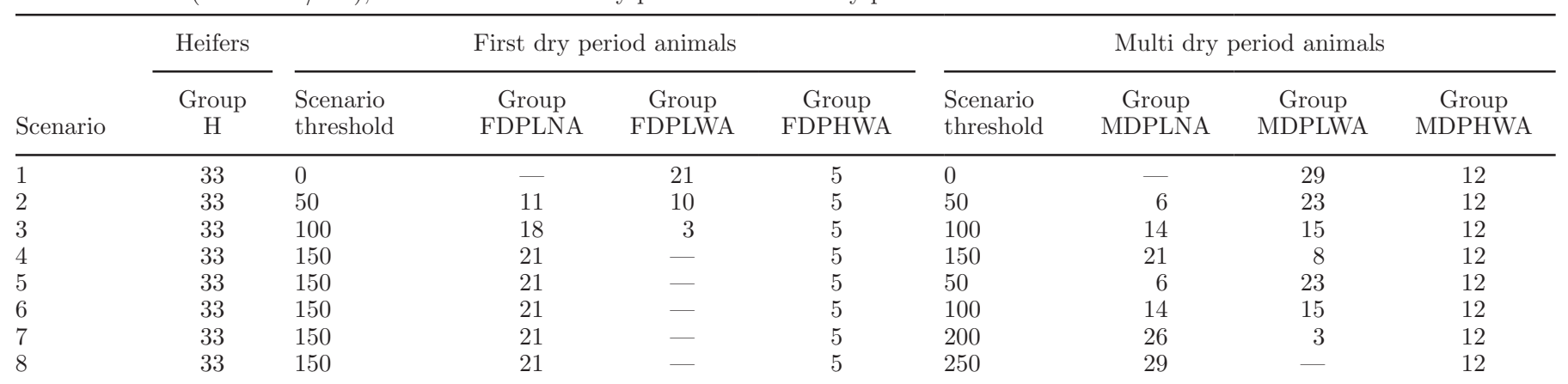

${ }^{1}$ FDPLNA $=$ first dry period animals with SCC at drying off $<$ scenario threshold, dried off without antimicrobials; FDPLWA $=$ first dry period animals with SCC at drying off $\geq$ scenario threshold and $<$ trial threshold, dried off with antimicrobials; FDPHWA = first dry period animals with SCC at drying off $\geq$ trial threshold, dried off with antimicrobials; MDPLNA = multi dry period animals with SCC at drying off $<$ scenario threshold, dried off without antimicrobials; MDPLWA $=$ multi dry period animals with SCC at drying off $\geq$ scenario threshold and $<$ trial threshold, dried off with antimicrobials; MDPHWA = multi dry period animals with SCC at drying off $\geq$ trial threshold, dried off with antimicrobials.

sis, all data were checked for unlikely values, but no data were excluded for that reason.

\section{Clinical Mastitis}

Clinical mastitis analysis were based on IRCM in the different groups as described above. Clinical mastitis data of cows below the trial threshold were based on $\mathrm{CM}$ cases as recorded by the farmers in the specific groups in the field trial (Scherpenzeel et al., 2014). The IRCM at quarter level (QIRCM) was calculated as the number of quarter cases per quarter-day at risk. Quarters were at risk during the time the cow was enrolled in the study; that is, from the day of drying off until 100 DIM, unless a quarter was censored due to CM or other reasons. Repeat cases of $\mathrm{CM}$ were not recorded and therefore not included in the analysis. To recalculate the QIRCM gathered from the within-cow comparison as an IRCM at cow-level (CIRCM) in groups FDPLNA, FDPLWA, MDPLNA, and MDPLWA, the QIRCM was adjusted for the average number of affected quarters per cow (= total number of quarter cases of CM in the field trial, divided by the total number of cows with $\mathrm{CM})$. The average number of quarters per cow with CM was also determined separately for the quarters that were dried off with and without antimicrobials (results not shown). Very little difference was observed between those groups and thus the overall average number of quarters with $\mathrm{CM}$ was used. The outcome was multiplied by 4 quarters per cow:

$$
\begin{aligned}
\mathrm{CIRCM} & =\left[\mathrm{QIRCM} / \frac{\text { total no. of quarter cases of } \mathrm{CM}}{\text { total no. of cows with } \mathrm{CM}}\right] \\
& \times 4 \text { quarters } / \text { cow. }
\end{aligned}
$$

For groups FDPLNA, FDPLWA, MDPLNA, and MDPLWA, the IRCM was calculated based on the results from the study, and multiplied by the number of cows in that specific group. For group H, a CIRCM of 1.4 $\times 10^{-3} \mathrm{CM}$ cases per cow-day at risk was assumed, and for groups FDPHWA and MDPHWA, a CIRCM of $2.2 \times 10^{-3} \mathrm{CM}$ cases per cow-day at risk, based on Barkema et al. (1998). The CIRCM was multiplied by the number of cows in the specific group. Heifers were included from the day of calving until 100 DIM. The example herd consisted of 33 heifers during the first 100 DIM and 67 multiparous cows during the dry period with an average length of $53 \mathrm{~d}$ and the first 100 DIM, leading to 13,551 cow-days at risk in a 100-cow dairy herd. The IRCM for the dry period and 100 DIM for the example herd (HIRCM) in CM cases per 10,000 cow-days at risk was calculated for scenarios 1 to 8 :

$$
\begin{gathered}
\text { HIRCM }_{1 \ldots 8}=\left[\left(1.4 \times 10^{-3} \times 33\right) \times 100 \mathrm{~d}\right] \\
+\left[\left(\Sigma\left(\mathrm{CIRCM}_{F D P L N A} \times n_{F D P L N A}\right)_{1 \ldots 8}\right.\right. \\
+\left(\mathrm{CIRCM}_{F D P L W A} \times n_{F D P L W A}\right)_{1 \ldots 8}+\left(2.2 \times 10^{-3} \times 5\right) \\
+\left(\mathrm{CIRCM}_{M D P L N A} \times n_{M D P L N A}\right)_{1 \ldots 8} \\
+\left(\mathrm{CIRCM}_{M D P L W A} \times n_{M D P L W A}\right)_{1 \ldots 8} \\
\left.\left.+\left(2.2 \times 10^{-3} \times 12\right)\right) \times 153 \mathrm{~d}\right] \div 1.3551,
\end{gathered}
$$

where $\mathrm{HIRCM}_{1 \ldots 8}=\mathrm{IRCM}$ in the example herd for scenarios 1 to 8; CIRCM $_{F D P L N A}, F D P L W A, M D P L N A$, and $M D P L W A=$ CIRCM in groups FDPLNA, FDPLWA, MDPLNA, and MDPLWA; and $n_{F D P L N A}$, FDPLWA, MDPLNA, and ${ }_{M D P L W A}=$ number of cows in groups FDPLNA, FDPLWA, MDPLNA, and MDPLWA. The number of cows and the CIRCM for groups FDPLNA, FDPLWA, 
Table 4. Incidence rate of clinical mastitis at cow level (values are $\times 10^{-3}$ cases per cow-day at risk) per dry off group for different scenarios for selective dry cow therapy (1-8) with their SCC thresholds $\left(\times 10^{3}\right.$ cells $\left./ \mathrm{mL}\right)$, for first dry period and multi dry period animals ${ }^{1}$

\begin{tabular}{|c|c|c|c|c|c|c|}
\hline \multirow[b]{2}{*}{ Scenario } & \multicolumn{3}{|c|}{ First dry period animals } & \multicolumn{3}{|c|}{ Multi dry period animals } \\
\hline & $\begin{array}{l}\text { Scenario } \\
\text { threshold }\end{array}$ & $\begin{array}{l}\text { Group } \\
\text { FDPLNA }\end{array}$ & $\begin{array}{l}\text { Group } \\
\text { FDPLWA }\end{array}$ & $\begin{array}{l}\text { Scenario } \\
\text { threshold }\end{array}$ & $\begin{array}{l}\text { Group } \\
\text { MDPLNA }\end{array}$ & $\begin{array}{c}\text { Group } \\
\text { MDPLWA }\end{array}$ \\
\hline 1 & 0 & - & 0.62 & 0 & - & 0.83 \\
\hline 2 & 50 & 0.62 & 0.59 & 50 & 1.26 & 0.80 \\
\hline 3 & 100 & 0.65 & 0.74 & 100 & 1.88 & 0.80 \\
\hline 4 & 150 & 0.74 & - & 150 & 1.60 & 0.99 \\
\hline 7 & 150 & 0.74 & - & 200 & 1.63 & 0.46 \\
\hline 8 & 150 & 0.74 & - & 250 & 1.63 & - \\
\hline
\end{tabular}

${ }^{1}$ FDPLNA $=$ first dry period animals with SCC at drying off $<$ scenario threshold, dried off without antimicrobials; FDPLWA $=$ first dry period animals with SCC at drying off $\geq$ scenario threshold and $<$ trial threshold, dried off with antimicrobials; MDPLNA = multi dry period animals with SCC at drying off $<$ scenario threshold, dried off without antimicrobials; MDPLWA = multi dry period animals with SCC at drying off $\geq$ scenario threshold and $<$ trial threshold, dried off with antimicrobials.

MDPLNA, and MDPLWA per scenario are shown in Tables 3 and 4 .

\section{Subclinical Mastitis}

Quarters with SCC >200,000 cells $/ \mathrm{mL}$ and no signs of CM at 14 DIM were considered as subclinically infected, and therefore QSCC $>200$ was used to determine the prevalence of subclinical mastitis at 14 DIM. To calculate the number of cows with one or more quarters with QSCC > 200 (CSCC200) based on the data gathered from the within-cow comparison in the field trial, QSCC $>200$ was adjusted for the average number of high-SCC quarters per cow (total number of QSCC $>200$ in the field trial, divided by the total number of cows with one or more QSCC $>200$ ). The average number of high-SCC quarters per cow was also determined separately for the quarters that were dried off with and without antimicrobials (results not shown). Very little difference was observed between those groups and thus the overall average number of high-SCC quarters was used. The outcome was multiplied by 4 quarters per cow:

$$
\begin{aligned}
\mathrm{CSCC} 200 & = \\
& {\left[\mathrm{QSCC}>200 / \frac{\text { total no. of } \mathrm{QSCC}>200}{\text { total no. of cows with } \mathrm{QSCC}>200}\right] } \\
& \times 4 \text { quarters } / \text { cow. }
\end{aligned}
$$

For groups FDPLNA, FDPLWA, MDPLNA, and MDPLWA, the prevalence of CSCC200 cases was calculated based on the results from the field trial, and multiplied by the number of cows in that specific group. For group $\mathrm{H}$, a CSCC200 at 14 DIM of $40 \%$, and for groups FDPHWA and MDPHWA, a CSCC200 at 14 DIM of 53\% was assumed, based on Sampimon et al. (2010). The CSCC200 was multiplied by the number of cows in that specific group. The CSCC200 for the example herd (HSCC200) was calculated for the different scenarios by summing the results of the different groups:

$$
\begin{gathered}
\operatorname{HSCC} 200_{1 \ldots 8}=(0.40 \times 33) \\
+\left(\mathrm{CSCC} 200_{\text {FDPLNA }} \times n_{\text {FDPLNA }}\right)_{1 \ldots 8} \\
+\left(\mathrm{CSCC} 200_{\text {FDPLWA }} \times n_{\text {FDPLWA }}\right)_{1 \ldots 8} \\
+(0.53 \times 5) \\
+\left(\mathrm{CSCC} 200_{\text {MDPLNA }} \times n_{\text {MDPLNA }}\right)_{1 \ldots 8} \\
+\left(\mathrm{CSCC} 200_{\text {MDPLWA }} \times n_{\text {MDPLWA }}\right)_{1 \ldots 8} \\
+(0.53 \times 12),
\end{gathered}
$$

where HSCC200 ${ }_{1 . .8}=$ prevalence of CSCC200 cases in the example herd for scenarios 1 to 8; CSCC200 ${ }_{F D P L N A}$, FDPLWA, MDPLNA, MDPLWA $=$ CSCC200 in groups FDPLNA, FDPLWA, MDPLNA, and MDPLWA; and $n_{F D P L N A}$, FDPLWA, MDPLNA, MDPLWA $=$ number of cows in groups FDPLNA, FDPLWA, MDPLNA, and MDPLWA.

\section{Antimicrobial Usage}

Data on all individual antimicrobial treatments regarding udder health were collected during the field trial, comprising active compound, application route, dosage, frequency, and duration of treatment.

Antimicrobial usage for DCT and CM treatments was expressed as the number of animal daily dosages (ADD) for each of the scenarios in the example herd. One ADD is defined as a standardized 1-d treatment, being the average dose for a 1-d treatment of a registered veterinary drug for its main indication, as described in detail previously (Scherpenzeel et al., 2014). 
In this calculation, DCT of one quarter was calculated as 1 ADD according to the definitions provided by the Dutch Veterinary Medicines Authority (SDa, 2014). Intramammary antimicrobial treatments as well as parenteral antimicrobial treatments related to $\mathrm{CM}$ were allocated to the affected quarters and summed per CM case. The average ADD per CM case was calculated and used to estimate antimicrobial usage for $\mathrm{CM}$ in the different scenarios in the example herd by multiplying the number of $\mathrm{CM}$ cases by this average ADD per CM case. Antimicrobial usage for DCT was calculated based on the number of cows in the different groups in the different scenarios. Subsequently, antimicrobial usage due to DCT and CM in the dry period and first 100 DIM was summed for each of the scenarios in the example herd.

\section{Economic Analysis}

To calculate the economic consequences for each of the scenarios in the example herd, the total costs related to DCT, CM in the dry period and the first 100 DIM, and SCM were calculated. All calculations were done in euros.

The default economic losses for a CM case were set at $€ 221$, an average taken from Huijps et al. (2008), who calculated $€ 235$ for mo 1, €225 for mo 2, and €204 for mo 3 after calving. For each scenario, the costs of CM were calculated as the total number of $\mathrm{CM}$ cases in the example herd times €221.

The economic losses for SCM were calculated as milk production losses due to SCM multiplied by the related costs per kilogram of milk loss. Halasa et al. (2009) estimated milk production losses for different levels of increased SCC without differentiating parities. The average milk production loss of all cows with cow-level SCC $>200,000$ cells $/ \mathrm{mL}$ was $0.81 \mathrm{~kg} / \mathrm{d}$ (Halasa et al., 2009). Average duration of a SCM case, irrespective of the causative pathogen, was set at $80 \mathrm{~d}$, based on Lam et al. (1997). The costs of production losses due to SCM in a nonquota system were set at $€ 0.25 / \mathrm{kg}$, adapted from Huijps et al. (2008). The prevalence of SCM at 14 DIM was used to calculate differences in economic losses due to SCM in the different scenarios. Thus, the economic losses for a case of SCM were $€ 16.20$ for cows in all groups in the example herd. For each scenario, the costs of SCM of the cows in all groups were summed.

The costs of DCT consisted of antimicrobials and labor of the farmer. It was estimated that it took on average 15 min to dry off a cow correctly, at an hourly rate of $€ 18$, leading to $€ 4.50$ per cow (Halasa et al., 2009). The costs for dry-cow antimicrobials were set at $€ 10 /$ cow (Halasa et al., 2009). For each scenario, DCT costs were calculated by multiplying the total number of cows dried off with antimicrobials by $€ 14.50$. Finally, costs of CM, SCM, and DCT were summed for each of the scenarios.

\section{Sensitivity Analysis}

As described above, the model used was based on data from a large field trial (Scherpenzeel et al., 2014). Clinical and subclinical mastitis data of cows below the trial threshold were based on CM cases as recorded by the farmers and on QSCC $>200$ data measured in the specific groups in the field trial. For groups H, FDPHWA, and MDPHWA, CIRCM and SCC200 were based on literature from Barkema et al. (1998) and Sampimon et al. (2010).

A sensitivity analysis was performed to evaluate the effect of variation in the most important input variable, HIRCM, on the most important output variables, antimicrobials, and estimated costs. Herd-level IRCM was varied by halving and doubling the effect of SDCT, multiplying QIRCM by 0.5 as the lower limit and by 2.0 as the upper limit for all age groups in the scenarios. The sensitivity analysis was carried out for all scenarios to determine the effect on antimicrobial usage and estimated costs.

\section{RESULTS}

\section{Clinical Mastitis}

In the 1,657 cows in the 97 study herds in the field trial, 319 quarter cases of $\mathrm{CM}$ in 243 cows were recorded during the dry period and 100 DIM, with a QIRCM of $0.32 \times 10^{-3}$ cases per quarter-day at risk with, on average, $1.3 \mathrm{CM}$ quarters per cow.

The CIRCM for groups FDPLNA, FDPLWA, MDPLNA, and MDPLWA in the example herd are presented in Table 4. Over all scenarios and all SCC thresholds, CIRCM was higher in quarters of MDP compared with FDP animals, especially when no DCT was applied.

For FDP animals, there was no substantial difference in CIRCM using different thresholds. The CIRCM varied from 0.59 to $0.74 \times 10^{-3}$ cases per cow-day at risk. For MDP animals, however, differences in CIRCM between scenarios were greater (Table 4).

The HIRCM for different scenarios in the example herd are presented in Figure 1 and Table 5. The HIRCM in the example herd varied from 11.6 to 14.5 cases of CM per 10,000 cow-days at risk in the different scenarios.

Scenario 1 (BDCT) had the lowest HIRCM with 11.6 CM cases per 10,000 cow-days at risk. The SCDT scenarios with the lowest HIRCM were scenario $2(50 / 50)$ 
Table 5. Evaluation of different scenarios for selective dry cow therapy (1-8) with their SCC thresholds $\left(\times 10^{3}\right.$ cells $/ \mathrm{mL}$ ) for an example dairy herd of 100 calving cows, with respect to the incidence rate of clinical mastitis on herd level (HIRCM), prevalence of subclinical mastitis on herd level (HSCC200), antimicrobial usage (AB), and estimated costs $(€)$

\begin{tabular}{llcccc}
\hline Scenario & $\begin{array}{l}\text { Threshold } \\
\text { FDP/MDP }\end{array}$ & HIRCM $^{2}$ & HSCC200 & AB $^{3}$ & $€$ \\
\hline 1 & $0 / 0$ & 11.6 & 38.8 & 3.15 & 5,070 \\
2 & $50 / 50$ & 11.8 & 42.3 & 2.48 & 4,946 \\
3 & $100 / 100$ & 13.3 & 43.5 & 1.94 & 5,190 \\
4 & $150 / 150$ & 13.9 & 45.9 & 1.56 & 5,261 \\
5 & $150 / 50$ & 12.1 & 42.5 & 2.09 & 4,893 \\
6 & $150 / 100$ & 13.5 & 44.1 & 1.83 & 5,223 \\
7 & $150 / 200$ & 14.1 & 47.2 & 1.37 & 5,276 \\
8 & $150 / 250$ & 14.5 & 48.3 & 1.27 & 5,383 \\
\hline
\end{tabular}

${ }^{1}$ Scenario thresholds for first dry period (FDP) and multi dry period (MDP) animals.

${ }^{2}$ Expressed as clinical mastitis cases per 10,000 cow-days at risk.

${ }^{3}$ Expressed as animal daily dosages.

and scenario $5(150 / 50)$ with, respectively, 11.8 and 12.1 CM cases per 10,000 cow-days at risk. The highest HIRCM occurred in scenario $8(150 / 250)$ with an HIRCM of $14.5 \mathrm{CM}$ cases per 10,000 cow-days at risk.

\section{Subclinical Mastitis}

In the field trial, 1,003 cases of QSCC $>200$ at 14 DIM occurred in 652 cows, with a QSCC $>200$ preva- lence of $38.5 \%$ and, on average, 1.5 quarters with a high SCC per cow.

The HSCC200 for the different scenarios in the example herd are presented in Figure 2 and Table 5. The HSCC200 for the different scenarios in the example herd varied from $38.8 \%$ in scenario 1 (BDCT) to $48.3 \%$ in scenario $8(150 / 250)$.

The number of CSCC200 at 14 DIM for groups FDPLNA, FDPLWA, MDPLNA, and MDPLWA in the

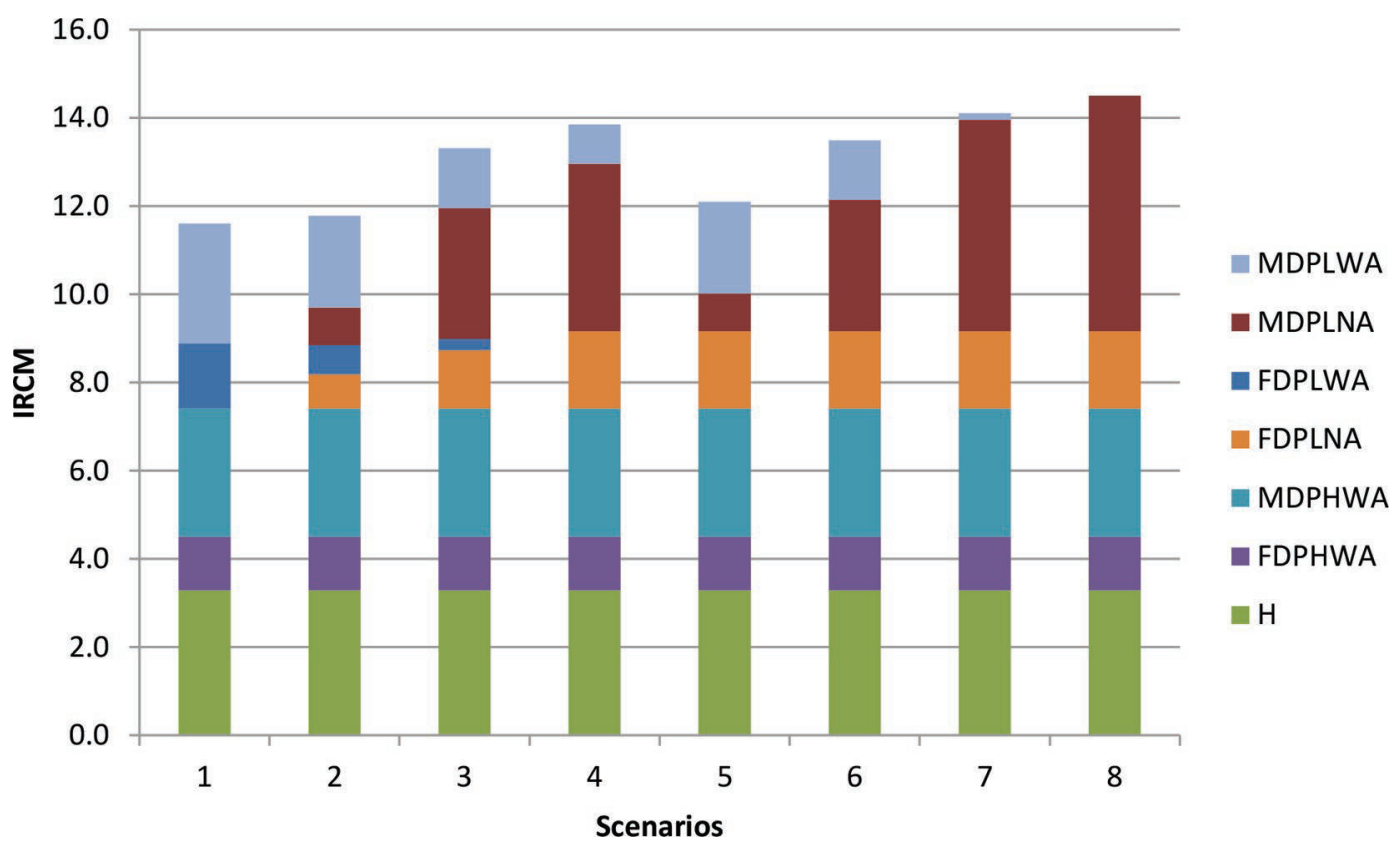

Figure 1. Estimated herd-level incidence rate of clinical mastitis (IRCM) per 10,000 cow-days at risk in an example dairy herd of 100 calving cows with different scenarios for selective dry cow therapy (1-8) based on specific treatment groups. MDPLWA = multi dry period animals with SCC at drying off $\geq$ scenario threshold and $<$ trial threshold, dried off with antimicrobials; MDPLNA $=$ multi dry period animals with SCC at drying off $<$ scenario threshold, dried off without antimicrobials; FDPLWA $=$ first dry period animals with SCC at drying off $>$ scenario threshold and $<$ trial threshold, dried off with antimicrobials; FDPLNA $=$ first dry period animals with SCC at drying off $<$ scenario threshold, dried off without antimicrobials; MDPHWA = multi dry period animals with SCC at drying off $\geq$ trial threshold, dried off with antimicrobials; FDPHWA $=$ first dry period animals with SCC at drying off $\geq$ trial threshold, dried off with antimicrobials; $\mathrm{H}=$ first-lactation heifers. Color version available online. 


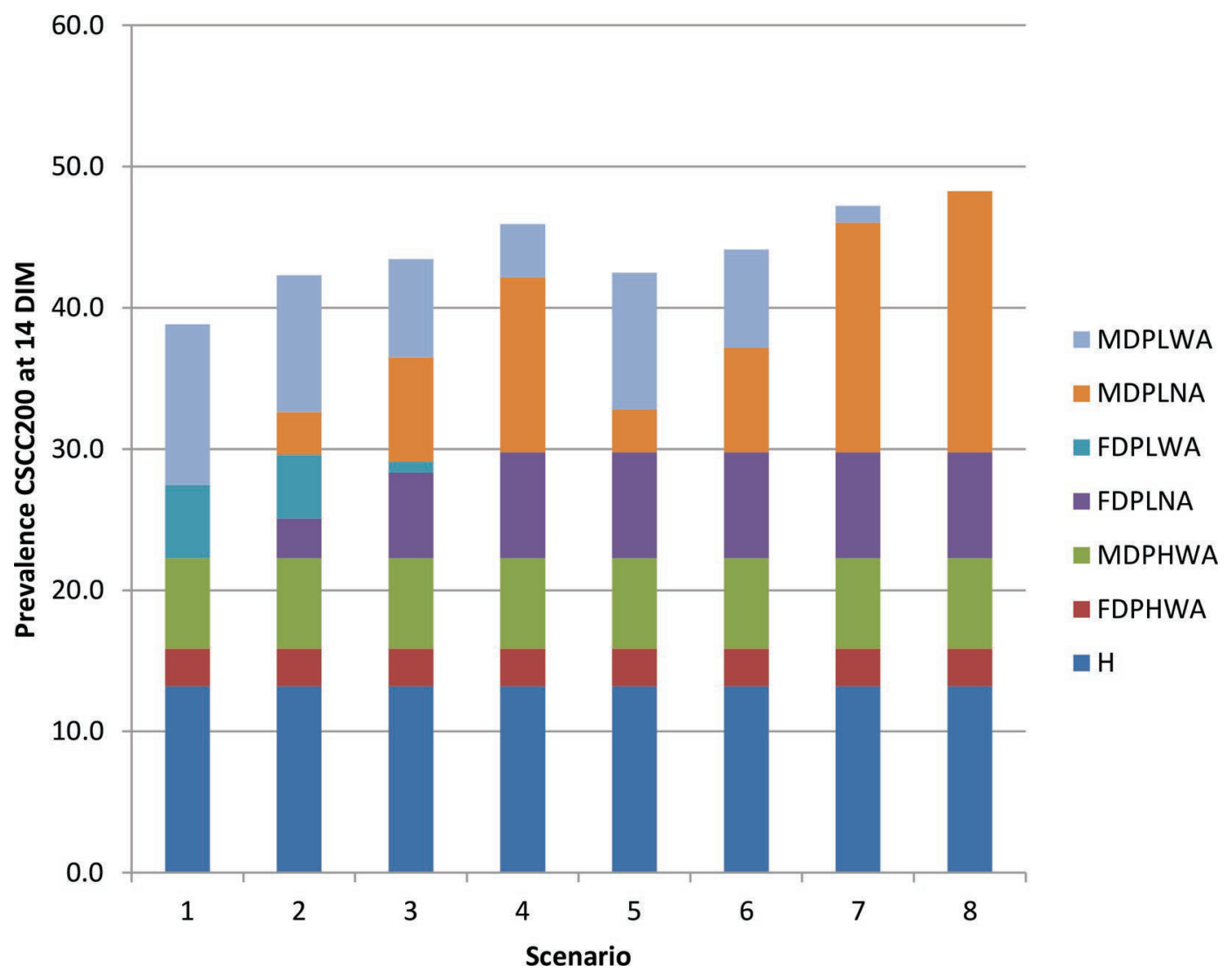

Figure 2. Estimated herd-level prevalence (\%) of cows with subclinical mastitis at cow level (CSCC200; one or more quarters with SCC $>200,000$ cells/mL) at 14 DIM in an example dairy herd of 100 calving cows with different scenarios for selective dry cow therapy (1-8) based on specific treatment groups. MDPLWA $=$ multi dry period animals with SCC at drying off $\geq$ scenario threshold and $<$ trial threshold, dried off with antimicrobials; MDPLNA = multi dry period animals with SCC at drying off $<$ scenario threshold, dried off without antimicrobials: FDPLWA $=$ first dry period animals with SCC at drying off $\geq$ scenario threshold and $<$ trial threshold, dried off with antimicrobials; FDPLNA $=$ first dry period animals with SCC at drying off $<$ scenario threshold, dried off without antimicrobials: MDPHWA $=$ multi dry period animals with SCC at drying off $\geq$ trial threshold, dried off with antimicrobials; FDPHWA = first dry period animals with SCC at drying off $\geq$ trial threshold, dried off with antimicrobials; $\mathrm{H}$ = first-lactation heifers. Color version available online.

Table 6. Number of cases of subclinical mastitis at cow level (one or more quarters with SCC >200,000 cells/mL) at 14 DIM, per dry off group, for different scenarios for selective dry cow therapy (1-8) with their SCC thresholds $\left(\times 10^{3}\right.$ cells $\left./ \mathrm{mL}\right)$, for first dry period and multi dry period animals $^{1}$

\begin{tabular}{|c|c|c|c|c|c|c|}
\hline \multirow[b]{2}{*}{ Scenario } & \multicolumn{3}{|c|}{ First dry period animals } & \multicolumn{3}{|c|}{ Multi dry period animals } \\
\hline & $\begin{array}{l}\text { Scenario } \\
\text { threshold }\end{array}$ & $\begin{array}{l}\text { Group } \\
\text { FDPLNA }\end{array}$ & $\begin{array}{l}\text { Group } \\
\text { FDPLWA }\end{array}$ & $\begin{array}{l}\text { Scenario } \\
\text { threshold }\end{array}$ & $\begin{array}{l}\text { Group } \\
\text { MDPLNA }\end{array}$ & $\begin{array}{l}\text { Group } \\
\text { MDPLWA }\end{array}$ \\
\hline 1 & 0 & - & 6.7 & 0 & - & 18.0 \\
\hline 2 & 50 & 3.6 & 5.9 & 50 & 4.5 & 15.6 \\
\hline 3 & 100 & 7.7 & 1.0 & 100 & 11.6 & 11.1 \\
\hline 4 & 150 & 9.6 & - & 150 & 19.4 & 6.1 \\
\hline 7 & 150 & 9.6 & - & 200 & 25.6 & 2.1 \\
\hline 8 & 150 & 9.6 & - & 250 & 29.3 & - \\
\hline
\end{tabular}

${ }^{1}$ FDPLNA $=$ first dry period animals with SCC at drying off $<$ scenario threshold, dried off without antimicrobials; FDPLWA $=$ first dry period animals with SCC at drying off $\geq$ scenario threshold and $<$ trial threshold, dried off with antimicrobials; MDPLNA = multi dry period animals with SCC at drying off $<$ scenario threshold, dried off without antimicrobials; MDPLWA = multi dry period animals with SCC at drying off $\geq$ scenario threshold and $<$ trial threshold, dried off with antimicrobials. 


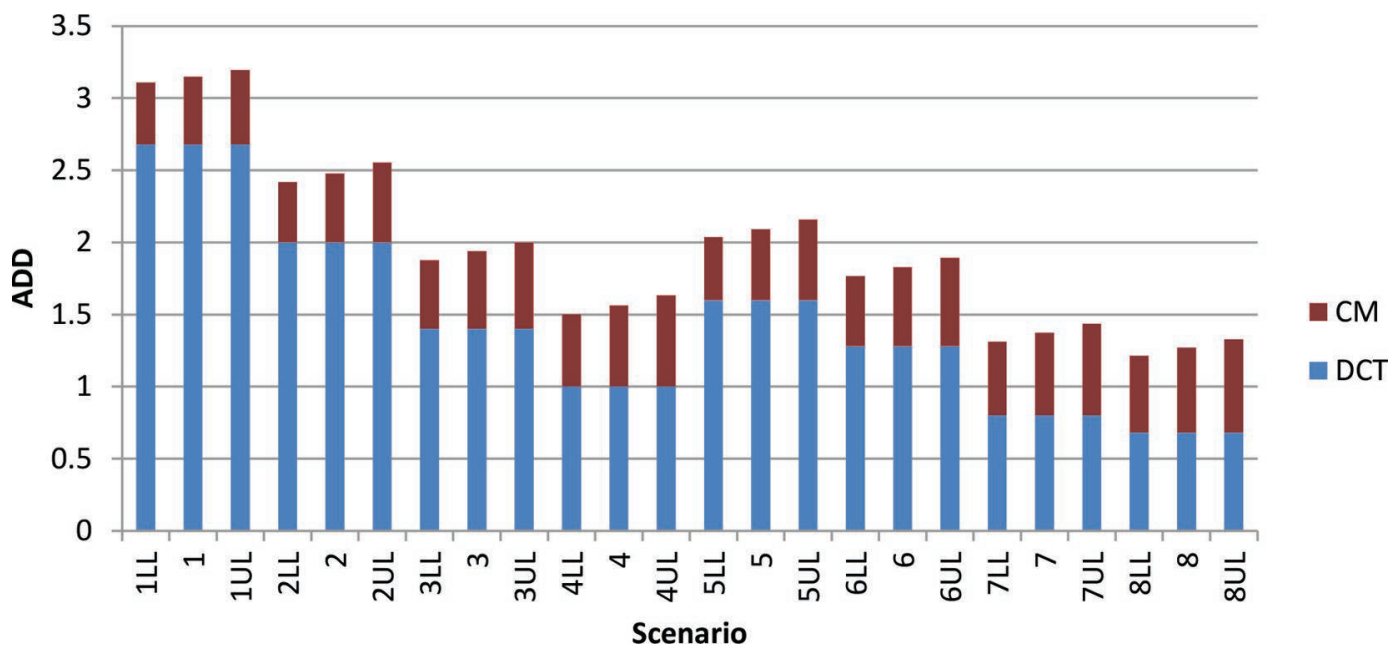

Figure 3. Estimated herd-level antimicrobial usage for dry cow therapy (DCT) and clinical mastitis (CM) expressed in animal daily dosages (ADD) in an example dairy herd of 100 calving cows with different scenarios for selective dry cow therapy (1-8). For each scenario, lower (LL) and upper (UL) limits are presented, indicating the herd-level antimicrobial usage if herd-level incidence rate of CM were halved or doubled. Color version available online.

example herd are presented in Table 6 . The prevalence of SCM was higher in MDP than in FDP animals when cows were dried off both with and without antimicrobials.

\section{Antimicrobial Usage}

Results on antimicrobial usage related to udder health were divided in DCT and CM treatments, and are presented for the different scenarios in Figure 3 and Table 5. The average antimicrobial usage per CM case was calculated to be 3.0 ADD, including both intramammary and parenteral treatment. Treatment of CM during the dry period and the first 100 DIM resulted in a maximum difference of 0.12 ADD between scenarios, with the highest and the lowest IRCM being scenario 1 (0.47 ADD) and scenario 8 (0.59 ADD) in the example herd, respectively (Figure 3). Given this small difference, potential effects due to different antimicrobial usage for $\mathrm{CM}$ in different groups were not analyzed further. For DCT, the differences in antimicrobial usage per group were much larger, with a maximum difference of $2.00 \mathrm{ADD}$ between $\mathrm{BDCT}$ (scenario 1; 2.68 ADD) and scenario 8 (0.68 ADD; Figure 3).

Total antimicrobial usage for DCT and CM treatment varied over the scenarios, from 1.27 ADD (scenario 8) to 3.15 ADD (scenario 1; Figure 3, Table 5), leading to a maximum reduction in antimicrobial usage of $60 \%$ for scenario 8 compared with BDCT. In none of the SDCT scenarios did additional antimicrobial treatment of $\mathrm{CM}$ exceed the total amount of antimicrobials saved for DCT.

\section{Economic Analysis}

The costs of DCT varied from $€ 972$ for BDCT to $€ 247$ for scenario 8. The costs of $\mathrm{CM}$ varied from $€ 3,470$ for BDCT to $€ 4,354$ for scenario 8. The costs of SCM varied from $€ 629$ for BDCT to $€ 782$ for scenario 8 (Figure 4). The total cost for each of the scenarios was found to have limited variability, varying from $€ 4,893$ for scenario 5 to $€ 5,383$ for scenario 8 (Table 5).

\section{Sensitivity Analysis}

The changes in herd-level antimicrobial usage and total costs related to DCT, CM, and SCM due to potential variability in HIRCM, evaluated in the sensitivity analysis, are presented in Figures 3 and 4 . The results of the model were influenced by a doubled or halved QIRCM, with estimated costs being more sensitive than antimicrobial usage to this change. The average increase over the scenarios for antimicrobial usage comparing the lower limit with the upper limit, was $+7.0 \%$, varying from $+2.8 \%$ to $+9.4 \%$. The average increase of the estimated costs in the different scenarios, comparing the lower limit with the upper limit, was $+18.7 \%$, varying from $+13.5 \%$ to $+22.1 \%$.

\section{DISCUSSION}

In this study, we evaluated the effect of different scenarios for selecting animals for DCT on udder health, antimicrobial usage, and economics. To control mastitis, BDCT has been used successfully in many parts of 
the world for quite some time and has been prescribed by the National Mastitis Council as part of their Mastitis Control Program (NMC, 2006). Due to a changing view on antimicrobial usage in the animal industry, preventive use of antimicrobials, including BDCT, is no longer allowed in several European countries, including the Netherlands. The consequences of SDCT depend on which cows are selected for DCT. Therefore, in this paper, we evaluated the effect of different scenarios for selecting cows for DCT.

Some studies have used quarter-, cow-, and herd-level criteria to select cows for dry cow therapy. Decisionmaking can be based on bacteriological culture (Robinson et al., 1988; Browning et al., 1990), SCC, and CM history (Rindsig et al., 1978; Torres et al., 2008; Rajala-Schultz et al., 2011), the California Mastitis Test (Rindsig et al., 1978; Bhutto et al., 2012), and $\mathrm{N}$-acetyl$\beta$-D-glucosaminidase (Hassan et al., 1999), with different accuracies in identification of infected cows. When used in herds with low bulk milk SCC $(<250,000$ cells/ $\mathrm{mL})$ to diagnose IMI in cows with a low SCC $(<200,000$ cells/mL) before drying off, a Petrifilm-based (3M, Minneapolis, MN) on-farm culture system for SDCT performed well, with a sensitivity of $85 \%$ and specificity of $73 \%$ (Cameron et al., 2013). Selecting cows for DCT with Petrifilm did not affect the risk of IMI at calving or the risk of a first case of $\mathrm{CM}$ in the first $120 \mathrm{~d}$ of lactation compared with BDCT (Cameron et al., 2014). The most feasible selection method, however, is based on monthly SCC, which has a reported sensitivity of $70 \%$ and specificity of $63 \%$ to identify quarters with IMI at drying off (Torres et al., 2008). In that study, the SCC cutoff level used was $<200,000$ cells/mL and no history of CM. Most of the studies described above compared SDCT with BDCT, where multiple (combinations of) selection criteria were used to administer SDCT. Our study compared 7 different SDCT scenarios based on monthly SCC with each other in addition to a BDCT scenario.

Dry-cow therapy affects udder health, which was quantified by the IRCM and the prevalence of SCM. Cows dried off without antimicrobials will have up to 1.7 times more CM and 1.6 times more SCM at 14 DIM than cows dried off with antimicrobials (Scherpenzeel et al., 2014). At the herd level, however, this effect is much smaller. The IRCM in the example herd varied from 11.6 to 14.5 cases of CM per 10,000 cow-days at risk for the different scenarios evaluated, in line with earlier reports on IRCM in Dutch dairy herds (Barkema et al., 1998; Sampimon et al., 2010; Lam et al., 2013). The prevalence of SCM at 14 DIM varied from 38.8 to $48.3 \%$ of cows with one or more quarters with SCC $>200,000$ cells $/ \mathrm{mL}$, which is somewhat higher than the findings of van den Borne et al. (2010). In the latter study, all cows were dried off with antimicrobials, leading to a subclinical mastitis prevalence of $12.8 \%$ for primiparous cows and $39.6 \%$ for multiparous cows (van den Borne et al., 2010).

Although the effect of DCT is of major importance (Scherpenzeel et al., 2014), it is only one of the manage-

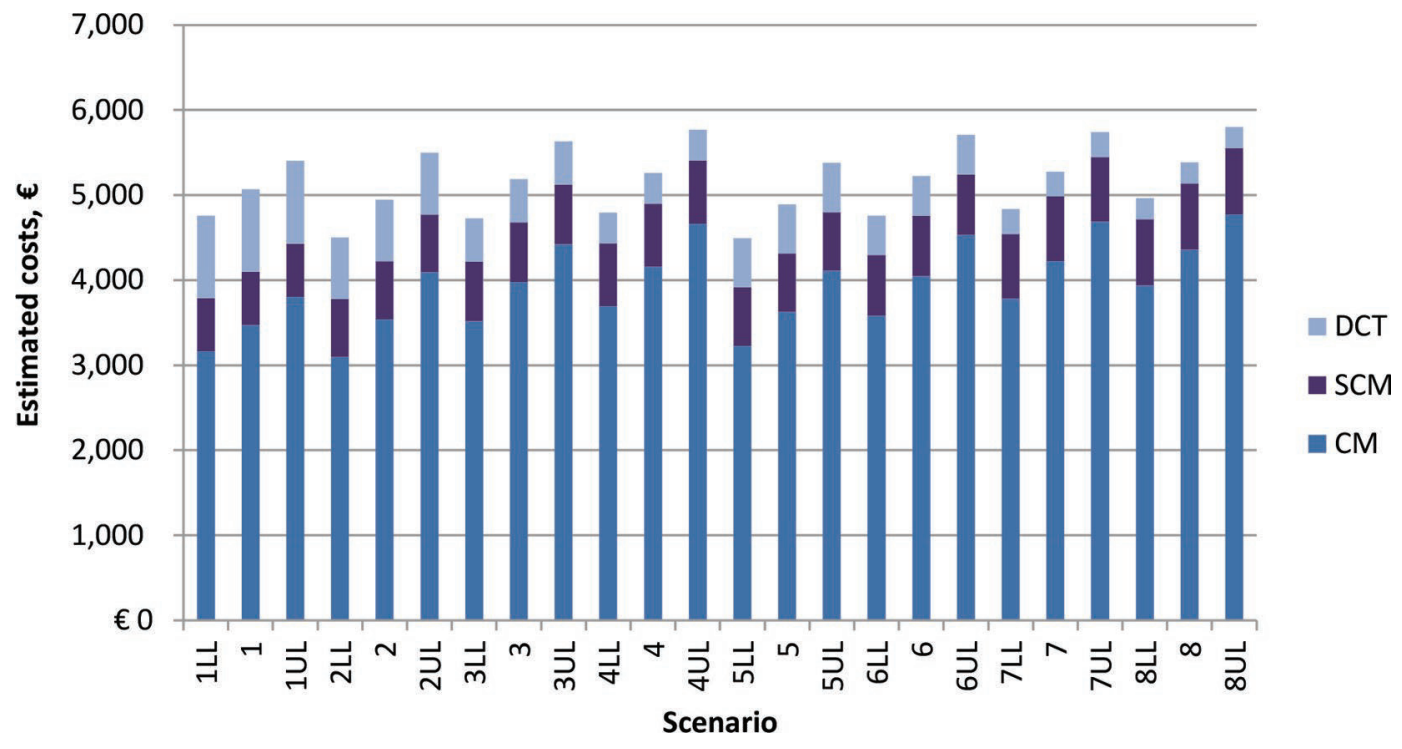

Figure 4. Estimated costs $(€)$ due to clinical mastitis (CM), subclinical mastitis (SCM), and dry-cow therapy (DCT) in an example dairy herd of 100 calving cows with different scenarios for selective dry cow therapy (1-8). For each scenario, lower limits (LL) and upper limits (UL) are presented, indicating the herd-level estimated costs if the herd-level incidence rate of CM were halved or doubled. Color version available online. 
ment factors influencing udder health. The prevalence of SCM at 14 DIM was lower in FDP than in MDP animals, which is in accordance with studies comparing SCM in heifers with multiparous cows (Fox, 2009; Santman-Berends et al., 2012). If more cows were left untreated with antimicrobials at drying off, higher IRCM and higher prevalence of SCM were seen. Thus, SCC thresholds to select cows for DCT do influence udder health for both FDP and MDP animals, although the effect was greater for MDP animals. Previous work in a BDCT situation also indicated that IRCM and SCM increased as parity increased (Barkema et al., 1998), demonstrating that the effect of SDCT is likely greater in MDP animals and that it may be wise to use different selection criteria for FDP and MDP animals.

Recalculating the effect of CM and SCM from the quarter level to the cow and herd levels of our data (that were based on a within-cow comparison in a field trial) may lead to an underestimation of effect (Scherpenzeel et al., 2014). The data were collected in low-SCC cows and were to be evaluated in an example herd situation, completed with data from literature. By definition, this leads to a proxy of the real-life situation, due to effects such as differences in composition of herds and herd dynamics. Because these biases are likely equal for the different scenarios evaluated, comparison of different scenarios is possible and the relative ranking seems robust. We chose a deterministic approach for our model and therefore cannot claim statistical differences between scenarios. Using a stochastic simulation model leads to an estimation of variance in results. To be able to use that approach, however, clear information on the actual variation in outcomes occurring, using different thresholds for selecting cows for DCT, would be needed. This information was not available. To collect that type of data, a herd-level intervention study would be needed, which would be very difficult, if not impossible, to perform, given the many factors apart from DCT that influence HIRCM.

Our goal was to evaluate herd-level effects of using different thresholds to select cows for drying off with antimicrobials. To our knowledge, no data on this topic have been published to date. We chose to use a deterministic model because that was accomplishable. The limitation of such a model is that some parameters and associations need to be assumed (e.g., the relationship between mastitis and production losses and risk of culling). We used the best available estimates for the Dutch situation to prevent potential bias as much as possible. The sensitivity analysis showed that the effect of variability in HIRCM has a limited effect on the herd-level antimicrobial usage, which is logical because most antimicrobials are used in DCT, which is a given in the scenarios used. The effect on economic results at the herd level is also limited, showing that the relative ranking of the scenarios is robust using our deterministic approach.

To calculate total antimicrobial usage on the herd level for different scenarios, antimicrobial usage for DCT and CM was summed. The average ADD per CM case was used in all calculations, because differences in antimicrobial usage due to $\mathrm{CM}$ between scenarios were very small compared with DCT (Figure 3). This may ignore possible differences in effect of parenteral versus intramammary use of antimicrobials on development of antimicrobial resistance. The same is true for differences between the effect on development of antimicrobial resistance of long-acting intramammary antimicrobials as used for DCT or an intramammary tube used for treatment of CM, both calculated as 1 ADD (Jensen et al., 2004). These effects were, however, outside the scope of this study.

Given the relatively low costs of dry-cow antimicrobials, economic consequences of SDCT are mainly influenced by CM and SCM, which are known to be expensive diseases (Hogeveen et al., 2011). Despite the simplification of the economic calculations presented in this paper, it is clear from an economic point of view that BDCT is not more attractive than SDCT. This is in line with the findings of Huijps and Hogeveen (2007). Our findings indicate that selecting cows on low SCC for SDCT does not predict if cows will or will not be infected with mastitis pathogens during the dry period.

When searching for optimal selection criteria for DCT, udder health and antimicrobial usage can be compared in an economic evaluation. This oversimplifies the potential effect of DCT on development of antimicrobial resistance, public opinion on preventive antimicrobial usage, political issues, and animal welfare. Although the perspective of animal welfare differs between citizens and farmers (Vanhonacker, 2008), mastitis, specifically CM, does affect animal welfare (Fogsgaard et al., 2015). Finally, for a system such as a selection protocol for DCT to be successfully implemented in practice, its applicability is important.

\section{CONCLUSIONS}

The effect of SDCT compared with BDCT on udder health, antimicrobial usage, and economics was influenced by the SCC criteria used to select cows for DCT. The SCC criteria chosen affect not only quantifiable parameters, such as udder health, antimicrobial usage, and economics, but also nonquantifiable parameters, such as welfare and practical achievability. Depending on the weight given to these parameters, optimal selection criteria should be chosen when implementing SDCT. 


\section{ACKNOWLEDGMENTS}

This study was financially supported by the Dutch Dairy Board (PZ, Zoetermeer, the Netherlands).

\section{REFERENCES}

Barkema, H. W., Y. H. Schukken, T. J. G. M. Lam, M. L. Beiboer, H Wilmink, G. Benedictus, and A. Brand. 1998. Incidence of clinical mastitis in dairy herds grouped in three categories by bulk milk somatic cell counts. J. Dairy Sci. 81:411-419.

Berry, E. A., and J. E. Hillerton. 2002. The effect of selective dry cow treatment on new intramammary infections. J. Dairy Sci. $85: 112-121$.

Bhutto, A. L., R. D. Murray, and Z. Woldehiwet. 2012. California mastitis test scores as indicators of subclinical intra-mammary infections at the end of lactation in dairy cows. Res. Vet. Sci. 92:13-17.

Bradley, A. J., and M. J. Green. 2000. A study of the incidence and significance of intramammary enterobacterial infections acquired during the dry period. J. Dairy Sci. 83:1957-1965

Browning, J. W., G. A. Mein, M. Barton, T. J. Nicholls, and P. Brightling. 1990. Effects of antibiotic therapy at drying off on mastitis in the dry period and early lactation. Aust. Vet. J. 67:440-442.

Cameron, M., G. P. Keefe, J. P. Roy, I. R. Dohoo, K. A. MacDonald, and S. L. McKenna. 2013. Evaluation of a 3M Petrifilm on-farm culture system for the detection of intramammary infection at the end of lactation. Prev. Vet. Med. 111:1-9.

Cameron, M., S. L. McKenna, K. A. MacDonald, I. R. Dohoo, J. P. Roy, and G. P. Keefe. 2014. Evaluation of selective dry cow treatment following on-farm culture: Risk of postcalving intramammary infection and clinical mastitis in the subsequent lactation. J. Dairy Sci. 97:270-284.

Chantziaras, I., F. Boyen, B. Callens, and J. Dewulf. 2014. Correlation between veterinary antimicrobial use and antimicrobial resistance in food-producing animals: A report on seven countries. J. Antimicrob. Chemother. 69:827-834.

CRV. 2014. Jaarstatistieken 2014: Dutch Royal Cattle Syndicate Annual Report (in Dutch). Accessed April 12, 2015. https://www. crv4all.nl/downloads/prestaties/jaarstatistieken.

de Haas, Y., W. Ouweltjes, J. ten Napel, J. J. Windig, and G. de Jong. 2008. Alternative somatic cell count traits as mastitis indicators for genetic selection. J. Dairy Sci. 91:2501-2511.

Dodd, F. H., D. R. Westgarth, F. K. Neave, and R. G. Kingwill. 1969 Mastitis - The strategy of control. J. Dairy Sci. 52:689-695.

Dufour, S., I. R. Dohoo, H. W. Barkema, L. DesCôteaux, T.-J. Devries, K. K. Reyher, J. P. Roy, and D. T. Scholl. 2012. Manageable risk factors associated with the lactational incidence, elimination, and prevalence of Staphylococcus aureus intramammary infections in dairy cows. J. Dairy Sci. 95:1283-1300.

Fogsgaard, K. K., T. W. Bennedsgaard, and M. S. Herskin. 2015. Behavioral changes in freestall-housed dairy cows with naturally occurring clinical mastitis. J. Dairy Sci. 98:1730-1738.

Fox, L. K. 2009. Prevalence, incidence and risk factors of heifer mastitis. Vet. Microbiol. 134:82-88.

Halasa, T., M. Nielen, A. P. De Roos, R. Van Hoorne, G. de Jong, T. J. G. M. Lam, T. van Werven, and H. Hogeveen. 2009. Production loss due to new subclinical mastitis in Dutch dairy cows estimated with a test-day model. J. Dairy Sci. 92:599-606.

Hassan, Z., R. C. Daniel, D. O'Boyle, and A. J. Frost. 1999. Effects of dry cow intramammary therapy on quarter infections in the dry period. Vet. Rec. 145:635-639.

Hogeveen, H., K. Huijps, and T. J. G. M. Lam. 2011. Economic aspects of mastitis: New developments. N. Z. Vet. J. 59:16-23.

Huijps, K., and H. Hogeveen. 2007. Stochastic modeling to determine the economic effects of blanket, selective, and no dry cow therapy. J. Dairy Sci. 90:1225-1234.
Huijps, K., T. J. G. M. Lam, and H. Hogeveen. 2008. Costs of mastitis: Facts and perception. J. Dairy Res. 75:113-120.

Jensen, V. F., E. Jacobsen, and F. Bager. 2004. Veterinary antimicrobial-usage statistics based on standardized measures of dosage. Prev. Vet. Med. 64:201-215.

Lam, T. J. G. M., Y. H. Schukken, J. H. van Vliet, F. J. Grommers, M. J. Tielen, and A. Brand. 1997. Effect of natural infection with minor pathogens on susceptibility to natural infection with major pathogens in the bovine mammary gland. Am. J. Vet. Res. 58:17-22.

Lam, T. J. G. M., B. H. van den Borne, J. Jansen, K. Huijps, J. C. van Veersen, G. van Schaik, and H. Hogeveen. 2013. Improving bovine udder health: A national mastitis control program in the Netherlands. J. Dairy Sci. 96:1301-1311.

Neave, F. K., F. H. Dodd, R. G. Kingwill, and D. R. Westgarth. 1969. Control of mastitis in the dairy herd by hygiene and management. J. Dairy Sci. 52:696-707.

NMC. 2006. NMC Recommended mastitis control program. https:// www.nmconline.org/docs/NMCchecklistInt.pdf.

Oliver, S. P. S. E. Murinda, and B. M. Jayarao. 2011. Impact of antibiotic use in adult dairy cows on antimicrobial resistance of veterinary and human pathogens: a comprehensive review. Foodborne Pathog. Dis. 8:337-355.

Rajala-Schultz, P. J., A. H. Torres, and F. J. Degraves. 2011. Milk yield and somatic cell count during the following lactation after selective treatment of cows at dry-off. J. Dairy Res. 78:489-499.

Rindsig, R. B., R. G. Rodewald, A. R. Smith, and S. L. Spahr. 1978 Complete versus selective dry cow therapy for mastitis control. J. Dairy Sci. 61:1483-1497.

Robinson, T. C., E. R. Jackson, and A. Marr. 1988. Mastitis incidence in quarters with different infections status at drying off and calving in two treatment groups. Br. Vet. J. 144:166-173.

Sampimon, O., B. H. van den Borne, I. M. Santman-Berends, H. W. Barkema, and T. J. G. M. Lam. 2010. Effect of coagulase-negative staphylococci on somatic cell count in Dutch dairy herds. J. Dairy Res. 77:318-324.

Santman-Berends, I. M. G. A., R. G. M. Olde Riekerink, O. C. Sampimon, G. van Schaik, and T. J. G. M. Lam. 2012. Incidence of subclinical mastitis in Dutch dairy heifers in the first 100 days in lactation and associated risk factors. J. Dairy Sci. 95:2476-2484.

Scherpenzeel, C. G. M., I. E. M. den Uijl, G. van Schaik, R. G. M. Olde Riekerink, J. M. Keurentjes, and T. J. G. M. Lam. 2014 Evaluation of the use of dry cow antibiotics in low somatic cell count cows. J. Dairy Sci. 97:3606-3614.

Schukken, Y. H., J. Vanvliet, D. Vandegeer, and F. J. Grommers 1993. A randomized blind trial on dry cow antibiotic infusion in a low somatic cell count herd. J. Dairy Sci. 76:2925-2930.

SDa. 2014. Dutch Veterinary Medicines Authority; Usage of antibiotics in agricultural livestock in the Netherlands in 2013, in Dutch. Accessed April 12, 2015. http://www.autoriteitdiergeneesmiddelen.nl/en/publications.

Torres, A. H., P. J. Rajala-Schultz, F. J. Degraves, and K. H. Hoblet 2008. Using dairy herd improvement records and clinical mastitis history to identify subclinical mastitis infections at dry-off. J. Dairy Res. 75:240-247.

USDA. 2008. Dairy 2007. Part III: Reference of Dairy Cattle Health and Management Practices in the United States, 2007. \#N482.0908. USDA-Animal and Plant Health Inspection ServiceVeterinary Services, Centers for Epidemiology and Animal Health (USDA-APHIS-VS, CEAH), National Animal Health Monitoring System, Fort Collins, CO.

van den Borne, B. H. P., G. van Schaik, T. J. G. M. Lam, and M. Nielen. 2010. Variation in herd level mastitis indicators between primiand multiparae in Dutch dairy herds. Prev. Vet. Med. 96:49-55.

Vanhonacker, F. 2008. Do citizens and farmers interpret the concept of farm animal welfare differently. Livest. Sci. 116:126-136. 